\title{
Red blood cell distribution width to platelet ratio substantiates preoperative survival prediction in patients with newly-diagnosed glioblastoma
}

\author{
Matthias Schneider ${ }^{1}\left[\right.$. Niklas Schäfer ${ }^{2}$. Stefanos Apallas ${ }^{1}$. Anna-Laura Potthoff ${ }^{1}$. Christian Bode ${ }^{3}$. \\ Erdem Güresir ${ }^{1} \cdot$ Muriel Heimann ${ }^{1} \cdot$ Felix Lehmann $^{3}$ - Elisa Scharnböck ${ }^{1}$. Christina Schaub ${ }^{2} \cdot$ Hartmut Vatter $^{1}$. \\ Ulrich Herrlinger ${ }^{2} \cdot$ Patrick Schuss ${ }^{1}$
}

Received: 28 May 2021 / Accepted: 29 July 2021 / Published online: 4 August 2021

(c) The Author(s) 2021

\begin{abstract}
Object The conception of individual patient-adjusted treatment strategies is constantly emerging in the field of neurooncology. Systemic laboratory markers may allow insights into individual needs and estimated treatment benefit at an earliest possible stage. Therefore, the present study was aimed at analyzing the prognostic significance of preoperative routine laboratory values in patients with newly-diagnosed glioblastoma.

Methods Between 2014 and 2019, 257 patients were surgically treated for newly-diagnosed glioblastoma at the NeuroOncology Center of the University Hospital Bonn. Preoperative routine laboratory values including red blood cell distribution width (RDW) and platelet count were reviewed. RDW to platelet count ratio (RPR) was calculated and correlated to overall survival (OS) rates.

Results Median preoperative RPR was 0.053 (IQR 0.044-0.062). The receiver operating characteristic (ROC) curve indicated an optimal cut-off value for RPR to be 0.05 (AUC $0.62 ; \mathrm{p}=0.002,95 \%$ CI $0.544-0.685$ ). 101 patients (39\%) presented with a preoperative $\mathrm{RPR}<0.05$, whereas 156 patients $(61 \%)$ had a $\mathrm{RPR} \geq 0.05$. Patients with preoperative $\mathrm{RPR}<0.05$ exhibited a median OS of 20 months (95\% CI 17.9-22.1), which was significantly higher compared to a median OS of 13 months (95\% CI 10.9-15.1) in patients with preoperative $R P R \geq 0.05(\mathrm{p}<0.001)$.

Conclusions The present study suggests the RPR to constitute a novel prognostic inflammatory marker for glioblastoma patients in the course of preoperative routine laboratory examinations and might contribute to a personalized medicine approach.
\end{abstract}

Keywords Inflammation $\cdot$ Glioblastoma $\cdot$ Red blood cell distribution width $\cdot$ Platelet

\section{Introduction}

Despite many efforts, glioblastoma is still associated with a dismal prognosis and poses an interdisciplinary challenge to patient-centered collaboration for its treatment [1].

Matthias Schneider

matthias.schneider@ukbonn.de

1 Department of Neurosurgery, University Hospital Bonn, Venusberg-Campus 1, 53127 Bonn, Germany

2 Division of Clinical Neuro-Oncology, Department of Neurology, University Hospital Bonn, Bonn, Germany

3 Department of Anesthesiology and Intensive Care Medicine, University Hospital Bonn, Bonn, Germany
Therefore, an early and reliable prognostication of a patient's survival, preferably prior to surgery, is of utmost relevance [2]. The emphasis herein is not to withhold potential treatment options, but rather to tailor these therapeutic strategies to the individual needs of the patient or to their estimated benefit [3]. In addition to various efforts in identification of clinical risk features, laboratory markers represent a clearly objectifiable target of academic endeavors for early detection of patients at risk. Laboratory markers have also been used in other cancers to assess disease progression and/or survival in clinical practice $[4,5]$. Pierscianek et al. previously identified several laboratory parameters that might predict survival of patients with glioblastoma [6, 7]. Here, among the most promising markers, inflammatory parameters are consistently found to be associated with survival 
in glioblastoma patients. Inflammatory response has long been associated with assessment of cancer development, progression and prognosis. Nevertheless, non-specific laboratory values such as c-reactive protein (CRP), fibrinogen or white blood cell (WBC) count often represent imprecise parameters that may be influenced by various conditions. For example, preoperative administration of glucocorticoids is common practice in glioblastoma patients and may result in a cortison-induced leukocytosis associated with a poor prognosis [8]. However, more specific parameters (including differential blood work) are again often not part of the routinely collected preoperative laboratory values, making them unsuitable for widespread use.

To date, the prognostic value of red blood cell distribution width (RDW) has been noted for various diseases, most recently including various cancers [5, 9-11]. There are increasing reports emphasizing the inflammatory and also prognostic significance of the RDW to platelet count ratio (RPR) [12, 13]. Both RDW and platelet count belong to routine preoperative laboratory parameters, the former from a historical point of view to help classify eventual anemia. To our knowledge, the ratio calculated therefrom (RPR) has not yet been studied in its association with overall survival in glioblastoma patients.

Therefore, we analyzed patients with newly-diagnosed glioblastoma who had undergone surgery in our neurooncology center regarding the prognostic significance of preoperative routine laboratory values with a special focus on the RPR.

\section{Materials and methods}

\section{Patients}

All patients with newly diagnosed glioblastoma treated surgically at the authors' institution between 2014 and 2019 were entered into a computerized database (SPSS, version 25, IBM Corp., Armonk, NY). Approval was obtained from the institutional ethics committee for conducting the present study. To homogenize the patient cohort, only patients who underwent surgical resection were included, thus excluding patients with biopsy alone or no surgical intervention at all. In addition, only patients for whom the information listed below remained complete were included in further analysis.

To focus on the information available preoperatively, patient records were retrospectively reviewed for information such as patient characteristics, radiological features, results of preoperative laboratory tests, as well as functional neurological status at admission and during the course of treatment for further analysis. Thereby, the Karnofsky Performance Score (KPS) was used to grade patients according to their neurological functional status preoperatively, postoperatively, and during follow-up. In this regard, a KPS $\geq 70$ was defined as favorable outcome. Established prognostic factors, such as the extent of surgical resection, postoperative prolonged mechanical ventilation (PMV) and/ or additional molecular-pathological features (e.g., MGMT status) were discarded from additional multivariable analysis to focus solely on preoperatively available information. As previously reported, treatment decisions were reached in an interdisciplinary and consensus manner at the patient's initial presentation and during follow-up via the institutional tumor board meetings [14, 15].

Regarding laboratory analyses, values such as serum CRP $(\mathrm{CRP}<3 \mathrm{~g} / \mathrm{dl}$ versus [vs.] $\geq 3 \mathrm{~g} / \mathrm{dl})$, white blood cell (WBC) count ( $\leq 12 \mathrm{G} / \mathrm{l}$ vs. $>12 \mathrm{G} / \mathrm{l})$, platelet count, RDW ( $\leq 14 \%$ vs. $>14 \%$ ), and hemoglobin $(\mathrm{Hb})$ were obtained in the routine preoperative laboratory tests and dichotomized according to laboratory-defined normal-range values and/or previous experience [14, 16-18]. Anemia was defined sexspecific according to the World Health Organization (WHO) classification $(\mathrm{Hb}<12 \mathrm{~g} / \mathrm{dl}$ for women and $\mathrm{Hb}<13 \mathrm{~g} / \mathrm{dl}$ for men) [19].

Overall survival (OS) was measured from the day of glioblastoma surgery until death or last observation. All parameters were compared in relation to OS.

\section{Statistics}

Data analysis was accomplished using the SPSS computer software package (version 25, IBM Corp., Armonk, NY). Unpaired categorical and binary variables were analyzed in contingency tables using Fisher's exact test. For comparison of continuous variables, the Mann-Whitney U test was chosen since the data were mostly not normally distributed. To assess the discriminatory ability of the RPR in prognostic prediction, a receiver operating characteristic (ROC) curve was constructed within the studied patient population and the area under the curve (AUC) was calculated. A similar approach was taken for the optimal cut-off value for platelet count, as available literature provides sparse or contradictory information in this regard [20]. The optimal cut-off value for the corresponding values was determined from the curve over the given sensitivity and specificity. OS was analyzed with the Kaplan-Meier method using the Gehan-BreslowWilcoxon test. Results with $\mathrm{p}<0.05$ were considered statistically significant.

In addition, a multivariable logistic Cox regression model was constructed in order to identify independent preoperative predictors of OS in patients with glioblastoma undergoing surgical resection. 


\section{Results}

\section{Patient characteristics}

During the period from 2014 to 2019 , a total of 257 patients underwent surgical treatment for newly diagnosed glioblastoma at the Neuro-Oncology Center of the University Hospital Bonn and have been included in further analysis. Median age amounted to 64 years (interquartile range [IQR] 53-72 years). Patients reviewed for surgically treated glioblastoma in this study presented preoperatively with a median KPS of 90 (IQR 80-90). Gross-total resection (GTR) in the sense of complete removal of all contrast-enhancing tumor tissue was achieved in 176 patients $(69 \%)$, subtotal resection (STR) in 81 patients (31\%). Median OS (mOS) of the entire patient cohort with surgically treated glioblastoma was 16 months (95\% CI 14.2-17.8).

\section{Preoperative laboratory panel}

The median preoperative CRP level was $0.9 \mathrm{mg} / \mathrm{l}$ (IQR 0.4-2.7). Overall, 199 patients (77\%) demonstrated a $\mathrm{CRP}<3 \mathrm{mg} / \mathrm{l}$ preoperatively, while 58 patients $(23 \%)$ had a CRP $\geq 3 \mathrm{mg} / \mathrm{l}$. Patients with a preoperative CRP $<3 \mathrm{mg} / \mathrm{L}$ achieved a mOS of 16 months (95\% CI 14.1-17.9) compared to a mOS of 12 months (95\% CI 9.2-14.8) in patients with a preoperative $\mathrm{CRP} \geq 3 \mathrm{mg} / \mathrm{l}(\mathrm{p}=0.121)$.

Median WBC count in patients with glioblastoma requiring surgery was $10.5 \mathrm{G} / \mathrm{l}$ (IQR 7.3-15.2). Overall, 154 patients $(60 \%)$ demonstrated a WBC count $\leq 12 \mathrm{G} / 1$ preoperatively, while 103 patients (40\%) had a WBC count $>12$ G/l. In patients with a preoperative WBC count $\leq 12 \mathrm{G} / \mathrm{l}$ had mOS was 16 months (95\% CI 14.1-17.9) compared to a mOS of 15 months (95\% CI 10.9-19.1) in patients with a preoperative WBC count $>12 \mathrm{G} / \mathrm{l}(\mathrm{p}=0.655)$.

Patients with glioblastoma requiring surgery had a median platelet count of 247 G/l (IQR 214-294) preoperatively. The
ROC curve indicated the optimal cut-off value for platelet count in the present study cohort to be $260 \mathrm{G} / \mathrm{l}$ (AUC 0.60 ; $\mathrm{p}=0.006,95 \%$ CI $0.532-0.672$ ) with a sensitivity of $72 \%$ and a specificity of 52\%. Given this, 153 patients (60\%) presented with a platelet count $\leq 260 \mathrm{G} / 1$ preoperatively, whereas 104 patients $(40 \%)$ had a platelet count $>260 \mathrm{G} / \mathrm{l}$. In patients with a preoperative platelet count $>260 \mathrm{G} / 1$ survival was prolonged (mOS 20 months, 95\% CI 17.8-22.2) compared to patients with a preoperative platelet count $\leq 260 \mathrm{G} / \mathrm{l}$ (mOS 13 months, 95\% CI 10.8-15.2; p < 0.0001, Fig. 1A).

Median $\mathrm{Hb}$ level at the time of hospital admission prior to scheduled surgery for glioblastoma was $14.7 \mathrm{~g} / \mathrm{dl}$ (IQR 13.6-15.6). A total of 27 patients (11\%) with glioblastoma requiring surgery exhibited preoperative anemia (after sexspecific adjustments). Patients with preoperative anemia achieved a significantly lower mOS (9 months, 95\% CI 3.9-14.1) compared to the mOS of patients without preoperative prominent anemic laboratory findings (16 months, 95\% CI 14.2-17.8; $p=0.003$, Fig. 1B).

Median RDW in patients with glioblastoma requiring surgery was $12.9 \%$ (IQR 12.3-13.3). Overall, 231 patients (90\%) presented with a preoperative RDW $\leq 14 \%$, while 26 patients $(10 \%)$ had a preoperative RDW $>14 \%$. Patients with a preoperative RDW $\leq 14 \%$ exhibited a higher mOS (17 months, 95\% CI 15.2-18.7) compared to the mOS of patients with preoperative RDW $>14 \%$ ( 9 months, $95 \%$ CI $5.0-12.9 ; \mathrm{p}<0.001 ;$ Fig. 1C).

\section{Influence of RPR on overall survival}

Median RPR was 0.053 in patients with glioblastoma prior surgery (IQR 0.044-0.062). The ROC curve indicated the optimal cut-off value for RPR to be 0.05 (AUC $0.62 ; \mathrm{p}=0.002,95 \%$ CI $0.544-0.685)$ with a sensitivity of $71 \%$ and a specificity of $52 \%$. Given this, 101 patients (39\%) presented with a preoperative RPR $<0.05$, whereas 156 patients $(61 \%)$ had a RPR $\geq 0.05$. Table 1 depicts the distribution of known prognostic parameters in the
A

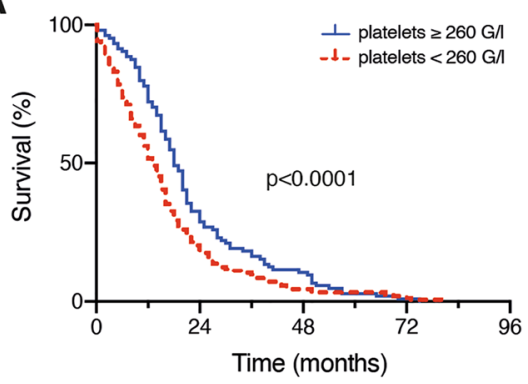

B

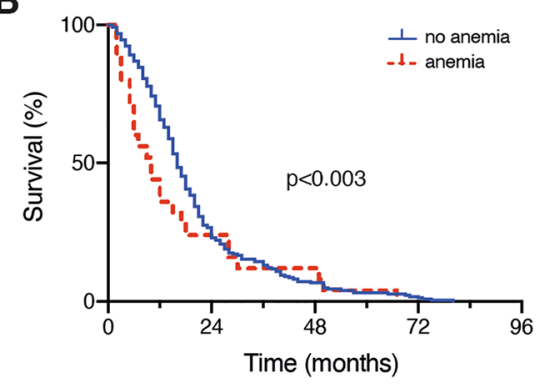

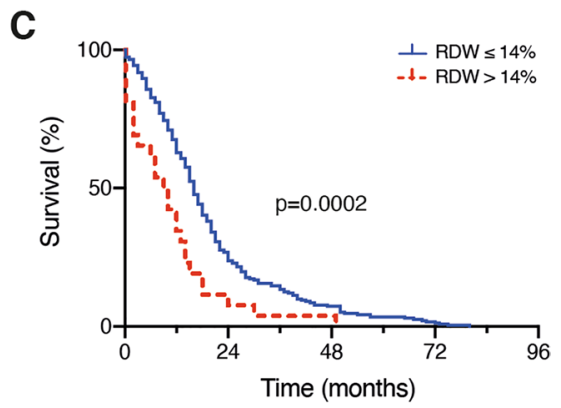

C

with newly-diagnosed glioblastoma. $R D W$ red blood cell distribution width, $O S$ overall survival
Fig. 1 Kaplan-Meier survival curves depict the influence of A preoperative platelet count $(\geq 260 \mathrm{G} / 1,<260 \mathrm{G} / \mathrm{l})$, B preoperative presence of anemia and $\mathbf{C}$ preoperative RDW $(\leq 14 \%,>14 \%)$ on OS in patients 
Table 1 Distribution of known prognostic parameters

\begin{tabular}{llcl}
\hline & $\mathrm{RPR}<0.05(\mathrm{n}=101)$ & $\mathrm{RPR} \geq 0.05(\mathrm{n}=156)$ & \\
\hline Median age (IQR) & $58(51-68)$ & $66(57-73)$ & $\mathrm{p}<0.0001$ \\
Preoperative KPS $\geq 70$ & $95(94 \%)$ & $149(96 \%)$ & $\mathrm{p}=0.8$ \\
GTR & $75(74 \%)$ & $101(65 \%)$ & $\mathrm{p}=0.1$ \\
MGMT non-methylated & $52(52 \%)^{*}$ & $90(59 \%)^{* *}$ & $\mathrm{p}=0.3$ \\
Postoperative PMV $(>24 \mathrm{~h})$ & $4(4 \%)$ & $14(9 \%)$ & $\mathrm{p}=0.1$ \\
\hline
\end{tabular}

*Information missing in 1 patient (1\%)

***Information missing in 4 patients $(3 \%)$

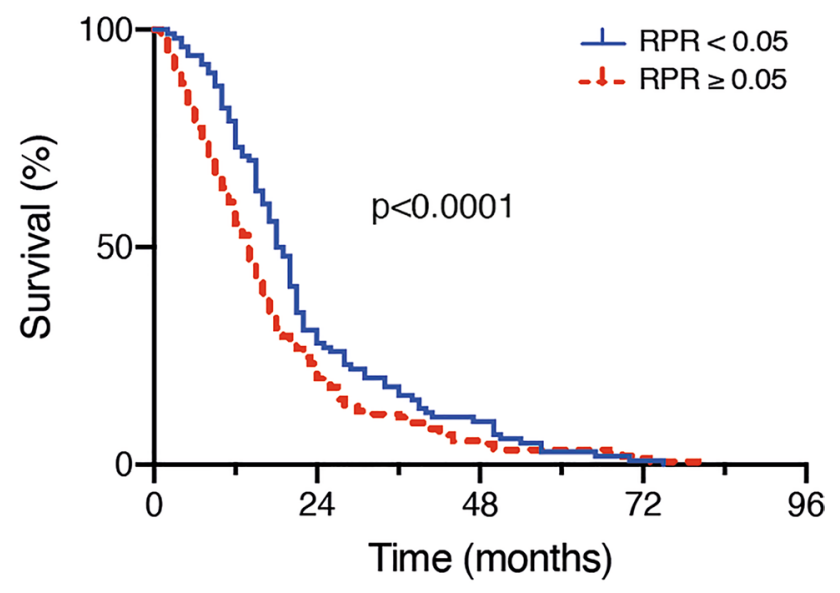

Fig. 2 Kaplan-Meier survival curves dependent on the preoperative RPR cut-off value of 0.05 in patients with newly-diagnosed glioblastoma. $R P R$ red blood cell distribution width to platelet count ratio

respective groups after the patient cohort was divided based on the determined RPR cut-off value.

In glioblastoma patients with preoperative RPR $<0.05$ median OS was 20 months (95\% CI 17.9-22.1), which was significantly higher compared to a median OS of 13 months (95\% CI 10.9-15.1) in patients with preoperative RPR $\geq 0.05$ ( $p<0.001$; Fig. 2).

\section{Multivariable analysis}

An additional multivariable survival analysis was performed to identify preoperatively-collectable independent predictors of OS available in patients with glioblastoma. The multivariable analysis identified the known variable "age $\geq 65$ years" $(\mathrm{p}<0.0001$, HR 2.2, 95\% CI 1.6-2.9) together with the laboratory value ratio "RPR $>0.05$ " $(\mathrm{p}=0.037$, HR $1.4,95 \%$ CI 1.1-1.8) as significant and independent preoperatively amenable predictors of poor OS in patients with glioblastoma requiring surgery.

\section{Discussion}

The present study identifies the red blood cell distribution width (RDW)-to-platelet ratio (RPR) as a laboratory value obtainable preoperatively which might be established as an independent predictor of OS in patients with glioblastoma requiring surgery.

Due to their aggressiveness and the persistently grim overall prognosis (despite all efforts), glioblastomas are an enormous burden for the affected patient, the family members/caregivers and also the treating physicians [21, 22]. An initial landmark assessment of the risk/benefit ratio is desirable prior to any potential treatment offer [15]. Various prognostic factors such as age, initial neurological status (KPS), extent of resection, MGMT status, and postoperative intensive care complications (PMV) have been established or suggested for this assessment [14, 15, 23]. However, a large part of this refers to the postoperative/biopsy situation, when information on resection extent, molecular pathology, and/or complicative course becomes available [24]. In the search for risk factors for overall survival that can be elected preoperatively if possible, laboratory indicators also repeatedly come to the fore $[4,7]$. Here, special attention is given to inflammatory markers. Many authors have previously highlighted a pivotal association between chronic inflammatory processes and the development/progression of tumors $[4,5,25,26]$. Indeed, it is well known that the carcinogenesis process implies a complex interaction of inflammatory cells in a specific local microenvironment in the tumor site [27-29]. These inflammatory processes take a decisive position in the stimulation of tumor growth, angiogenesis and further tumor infiltration [28]. Given that glioblastoma as such does not tend to metastasize outside the central nervous system, the assumption of a fundamental correlation and interaction between the systemic and local inflammation in the case of glioblastoma is not entirely comprehensible. There is growing evidence that exosomes among others may play an important role within these systemic inflammatory responses [30]. Along these lines, glioblastoma-derived exosomes have been shown to convert M1 macrophages into tumor-associated macrophages (TAMs) by transcriptional cellular reprogramming. These reprogrammed TAMs 
in turn produce exosomes that exert systemic inflammatory responses therefore highliting exosomes as effectors of key inflammation-related players [31]. Nevertheless, these experimental insights and also experience from other cancer entities have led to the identification of some hematologic prognostic parameters that, in the context of a low-cost and routinely collected preoperative blood test, could lead to better predictability and thus better management by focusing on patients at risk [26].

RDW has been established as a biomarker for predicting mortality in various diseases [32-35]. Nevertheless, the underlying pathophysiological mechanism remains mostly unexplained and thus-as often-statistical uncertainties are discussed. Nevertheless, the predictive ability of RDW, for example in cardiac diseases, remains undisputed despite multiple attempts [36]. RDW has also been found to be a prognosticator in a wide variety of cancers [37-39]. Where RDW has already gained prognostic value in predicting overall survival in patients with glioblastoma [18], the ratio formed from it together with platelet count (RPR) is experiencing increasing interest in other diseases [12, 13, 40, 41]. Platelet count as such is of unsteady predictive value. This is due to the fact that the normal distribution of platelet counts contains a range and not a cut-off value, so that the individually adjusted cut-off values in the individual studies are not comparable. In glioblastoma, an increase in platelet count was previously assumed to be an unfavorable prognostic feature [41]. This fits with the experience in most solid tumors that the elevated platelet count plays a critical role in progression and metastasis [42-44]. Presumed mechanisms include protecting circulating tumor cells from attacking the host's immune system as well as supporting proliferation of tumor cells [45]. However, glioblastoma differs from other solid tumors in the low to nearly absent frequency of systemically circulating tumor cells, which makes this argumentation of the observation regarding platelet count rather challenging to substantiate [46, 47]. In the present study, patients with an increased preoperative platelet count exhibited better OS in contrast to patients with a decreased count. Furthermore, the present study reveals a survival benefit for the group a low ratio of RDW to platelets, the RPR, which uses absolute numbers and thus can be derived from any routine blood test. RPR was first introduced to predict hepatic fibrosis in hepatitis [48]. Although the pathophysiological background of the inflammation marker RPR remains unclear, its elevation serves the probability of an increased RDW and a decreased platelet count. The advantage with regard to the platelet count is certainly the use of the count without prior cut-off limitation. However, in the present patient cohort, nonspecific inflammation markers such as CRP and WBC count do not seem to be suitable for preoperative prognostic assessment. This may be due to the non-specificity of these markers as well as to the possible adjustments prior to (semi-)elective surgery: in addition to the preoperative clarification of potential infection, the administration of glucocorticoids in glioblastoma patients should also be mentioned here.

Although the precise mechanism remains unclear, the present study indicates for the first time a potential prognostic value of the inflammatory marker RPR in glioblastoma patients.

\section{Limitations}

In addition to the retrospective design, the present work has further inherent limitations. These include the fact that the recorded and analyzed inflammatory laboratory values were preoperative in nature. In the case of (semi-)elective surgery and retrospective data collection, there is a risk that the actual deviation of the recorded laboratory values has already been corrected by preoperative measures. Nevertheless, this work considers the RPR as a preoperativelycollectable prognostic marker in glioblastoma patients for the first time and should thereby aid in accelerating further study efforts to validate this correlation in other neurooncological centers.

\section{Conclusions}

The present study suggests the RPR to constitute a novel prognostic inflammatory marker for glioblastoma patients in the course of preoperative routine laboratory examinations and might contribute to a personalized medicine approach.

Author contributions Conceptualization, MS and PS; data curation, MS, NS, SA, A-LP, MH and PS; formal analysis, MS, NS, SA, A-LP, UH and PS; writing — original draft preparation, MS and PS; writingreview and editing, MS, NS, SA, A-LP, CB, EG, MH, FL, ES, CS, HV, UH and PS; visualization, MS, A-LP and PS; supervision, MS, and PS.

Funding Open Access funding enabled and organized by Projekt DEAL. The authors received no financial support related to this study.

Data availability Restrictions apply to the availability of these data due to privacy restrictions.

Code availability Not applicable.

\section{Declarations}

Conflict of interest The authors declare that they have no conflict of interest.

Ethical approval The present study was approved by the local ethics committee at the University of Bonn. 
Consent to participate Informed consent was not sought as a retrospective study design was used.

Consent for publication All authors agreed to the publication of the manuscript.

Open Access This article is licensed under a Creative Commons Attribution 4.0 International License, which permits use, sharing, adaptation, distribution and reproduction in any medium or format, as long as you give appropriate credit to the original author(s) and the source, provide a link to the Creative Commons licence, and indicate if changes were made. The images or other third party material in this article are included in the article's Creative Commons licence, unless indicated otherwise in a credit line to the material. If material is not included in the article's Creative Commons licence and your intended use is not permitted by statutory regulation or exceeds the permitted use, you will need to obtain permission directly from the copyright holder. To view a copy of this licence, visit http://creativecommons.org/licenses/by/4.0/.

\section{References}

1. Weller M, van den Bent M, Preusser M, Le Rhun E, Tonn JC, Minniti G, Bendszus M, Balana C, Chinot O, Dirven L, French P, Hegi ME, Jakola AS, Platten M, Roth P, Ruda R, Short S, Smits M, Taphoorn MJB, von Deimling A, Westphal M, Soffietti R, Reifenberger G, Wick W (2021) EANO guidelines on the diagnosis and treatment of diffuse gliomas of adulthood. Nat Rev Clin Oncol 18:170-186. https://doi.org/10.1038/s41571-020-00447-z

2. Jarbe TU, Falk U, Mohammed AL, Archer T (1988) Acquisition and reversal of taste/tactile discrimination after forebrain noradrenaline depletion. Behav Neurosci 102:925-933. https:// doi.org/10.1037//0735-7044.102.6.925

3. Schneider M, Ilic I, Potthoff AL, Hamed M, Schäfer N, Velten M, Güresir E, Herrlinger U, Borger V, Vatter H, Schuss P (2020) Safety metric profiling in surgery for temporal glioblastoma: lobectomy as a supra-total resection regime preserves perioperative standard quality rates. J Neurooncol 149:455-461. https://doi. org/10.1007/s11060-020-03629-y

4. Schneider M, Schäfer N, Bode C, Borger V, Eichhorn L, Giordano FA, Güresir E, Heimann M, Ko YD, Lehmann F, Potthoff AL, Radbruch A, Schaub C, Schwab KS, Weller J, Vatter H, Herrlinger U, Landsberg J, Schuss P (2021) Prognostic value of preoperative inflammatory markers in melanoma patients with brain metastases. J Clin Med. https://doi.org/10.3390/jcm10040634

5. Wang Y, Hu X, Xu W, Wang H, Huang Y, Che G (2019) Prognostic value of a novel scoring system using inflammatory response biomarkers in non-small cell lung cancer: a retrospective study. Thorac Cancer 10:1402-1411. https://doi.org/10.1111/1759-7714. 13085

6. Pierscianek D, Ahmadipour Y, Oppong MD, Rauschenbach L, Kebir S, Glas M, Sure U, Jabbarli R (2019) Blood-based biomarkers in high grade gliomas: a systematic review. Mol Neurobiol 56:6071-6079. https://doi.org/10.1007/s12035-019-1509-2

7. Pierscianek D, Ahmadipour Y, Michel A, Chihi M, Oppong MD, Kebir S, Glas M, Stuschke M, Sure U, Jabbarli R (2020) Preoperative survival prediction in patients with glioblastoma by routine inflammatory laboratory parameters. Anticancer Res 40:11611166. https://doi.org/10.21873/anticanres.14058

8. Dubinski D, Won SY, Gessler F, Quick-Weller J, Behmanesh B, Bernatz S, Forster MT, Franz K, Plate KH, Seifert V, Harter PN, Senft C (2018) Dexamethasone-induced leukocytosis is associated with poor survival in newly diagnosed glioblastoma. J Neurooncol 137:503-510. https://doi.org/10.1007/s11060-018-2761-4

9. Duarte-Gamas L, Pereira-Neves A, Jacome F, Fragao-Marques M, Vaz RP, Andrade JP, Rocha-Neves JP (2020) Red blood cell distribution width as a 5-year prognostic marker in patients submitted to carotid endarterectomy. Cerebrovasc Dis Extra 10:181-192. https://doi.org/10.1159/000512587

10. Kim J, Kim K, Lee JH, Jo YH, Rhee JE, Kim TY, Kang KW, Kim YJ, Hwang SS, Jang HY (2012) Red blood cell distribution width as an independent predictor of all-cause mortality in out of hospital cardiac arrest. Resuscitation 83:1248-1252. https://doi. org/10.1016/j.resuscitation.2012.01.038

11. Salvagno GL, Sanchis-Gomar F, Picanza A, Lippi G (2015) Red blood cell distribution width: a simple parameter with multiple clinical applications. Crit Rev Clin Lab Sci 52:86-105. https:// doi.org/10.3109/10408363.2014.992064

12. Takeuchi H, Abe M, Takumi Y, Hashimoto T, Miyawaki M, Okamoto T, Sugio K (2019) Elevated red cell distribution width to platelet count ratio predicts poor prognosis in patients with breast cancer. Sci Rep 9:3033. https://doi.org/10.1038/ s41598-019-40024-8

13. Bilgin B, Sendur MAN, Hizal M, Dede DS, Akinci MB, Kandil SU, Yaman S, Yalcin A, Kilic M, Yalcin B (2019) Prognostic effect of red cell distribution width-to-platelet ratio in colorectal cancer according to tumor stage and localization. J Cancer Res Ther 15:54-60. https://doi.org/10.4103/jcrt.JCRT_624_17

14. Schuss P, Lehmann F, Schäfer N, Bode C, Scharnböck E, Schaub C, Heimann M, Potthoff AL, Weller J, Güresir E, Putensen C, Vatter H, Herrlinger U, Schneider M (2020) Postoperative prolonged mechanical ventilation in patients with newly diagnosed glioblastoma-an unrecognized prognostic factor. Front Oncol 10:607557. https://doi.org/10.3389/fonc.2020.607557

15. Schneider M, Potthoff AL, Scharnböck E, Heimann M, Schäfer N, Weller J, Schaub C, Jacobs AH, Güresir E, Herrlinger U, Vatter H, Schuss P (2020) Newly diagnosed glioblastoma in geriatric $(65+)$ patients: impact of patients frailty, comorbidity burden and obesity on overall survival. J Neurooncol 149:421427. https://doi.org/10.1007/s11060-020-03625-2

16. Auezova R, Ryskeldiev N, Doskaliyev A, Kuanyshev Y, Zhetpisbaev B, Aldiyarova N, Ivanova N, Akshulakov S, Auezova L (2016) Association of preoperative levels of selected blood inflammatory markers with prognosis in gliomas. Onco Targets Ther 9:6111-6117. https://doi.org/10.2147/OTT.S113606

17. Liang RF, Li M, Yang Y, Mao Q, Liu YH (2017) Significance of pretreatment red blood cell distribution width in patients with newly diagnosed glioblastoma. Med Sci Monit 23:3217-3223. https://doi.org/10.12659/msm.905204

18. Kaisman-Elbaz T, Elbaz Y, Merkin V, Dym L, Noy A, AtarVardi M, Bari R, Turiel S, Alt A, Zamed T, Eskira Y, Lavrenkov K, Kezerle Y, Dyomin V, Melamed I (2020) Hemoglobin levels and red blood cells distribution width highlights glioblastoma patients subgroup with improved median overall survival. Front Oncol 10:432. https://doi.org/10.3389/fonc.2020.00432

19. (1968) Nutritional anaemias. Report of a WHO scientific group. World Health Organization technical report series 405:5-37

20. Zaninetti C, Biino G, Noris P, Melazzini F, Civaschi E, Balduini CL (2015) Personalized reference intervals for platelet count reduce the number of subjects with unexplained thrombocytopenia. Haematologica 100:e338-340. https://doi.org/10.3324/ haematol.2015.127597

21. Weller J, Tzaridis T, Mack F, Steinbach JP, Schlegel U, Hau P, Krex D, Grauer O, Goldbrunner R, Bahr O, Uhl M, Seidel C, Tabatabai G, Brehmer S, Bullinger L, Galldiks N, Schaub C, Kebir S, Stummer W, Simon M, Fimmers R, Coch C, Glas M, Herrlinger U, Schäfer N (2019) Health-related quality of life and neurocognitive functioning with lomustine-temozolomide 
versus temozolomide in patients with newly diagnosed, MGMTmethylated glioblastoma (CeTeG/NOA-09): a randomised, multicentre, open-label, phase 3 trial. Lancet Oncol 20:1444-1453. https://doi.org/10.1016/S1470-2045(19)30502-9

22. Travers S, Litofsky NS (2021) Daily lifestyle modifications to improve quality of life and survival in glioblastoma: a review. Brain Sci. https://doi.org/10.3390/brainsci11050533

23. Sacko A, Hou MM, Temgoua M, Alkhafaji A, Marantidou A, Belin C, Mandonnet E, Ursu R, Doridam J, Coman I, Levy-Piedbois C, Carpentier AF (2015) Evolution of the karnosky performance status throughout life in glioblastoma patients. J Neurooncol 122:567-573. https://doi.org/10.1007/ s11060-015-1749-6

24. Ahmadipour Y, Jabbarli R, Gembruch O, Pierscianek D, Darkwah Oppong M, Dammann P, Wrede K, Ozkan N, Muller O, Sure U, El Hindy N (2019) Impact of multifocality and molecular markers on survival of glioblastoma. World Neurosurg 122:e461-e466. https://doi.org/10.1016/j.wneu.2018.10.075

25. Hao Y, Li X, Chen H, Huo H, Liu Z, Tian F, Chai E (2019) A Cumulative score based on preoperative neutrophil-lymphocyte ratio and fibrinogen in predicting overall survival of patients with glioblastoma multiforme. World Neurosurg 128:e427-e433. https://doi.org/10.1016/j.wneu.2019.04.169

26. Zheng SH, Huang JL, Chen M, Wang BL, Ou QS, Huang SY (2018) Diagnostic value of preoperative inflammatory markers in patients with glioma: a multicenter cohort study. J Neurosurg 129:583-592. https://doi.org/10.3171/2017.3.JNS161648

27. Morgillo F, Dallio M, Della Corte CM, Gravina AG, Viscardi G, Loguercio C, Ciardiello F, Federico A (2018) Carcinogenesis as a result of multiple inflammatory and oxidative hits: a comprehensive review from tumor microenvironment to gut microbiota. Neoplasia 20:721-733. https://doi.org/10.1016/j.neo.2018.05.002

28. Grivennikov SI, Greten FR, Karin M (2010) Immunity, inflammation, and cancer. Cell 140:883-899. https://doi.org/10.1016/j. cell.2010.01.025

29. Elinav E, Nowarski R, Thaiss CA, Hu B, Jin C, Flavell RA (2013) Inflammation-induced cancer: crosstalk between tumours, immune cells and microorganisms. Nat Rev Cancer 13:759-771. https://doi.org/10.1038/nrc3611

30. Othman N, Jamal R, Abu N (2019) Cancer-derived exosomes as effectors of key inflammation-related players. Front Immunol 10:2103. https://doi.org/10.3389/fimmu.2019.02103

31. Azambuja JH, Ludwig N, Yerneni SS, Braganhol E, Whiteside TL (2020) Arginase-1+ exosomes from reprogrammed macrophages promote glioblastoma progression. Int J Mol Sci. https://doi.org/ 10.3390/ijms21113990

32. Huang YL, Hu ZD, Liu SJ, Sun Y, Qin Q, Qin BD, Zhang WW, Zhang JR, Zhong RQ, Deng AM (2014) Prognostic value of red blood cell distribution width for patients with heart failure: a systematic review and meta-analysis of cohort studies. PLoS ONE 9:e104861. https://doi.org/10.1371/journal.pone.0104861

33. Xanthopoulos A, Giamouzis G, Melidonis A, Kitai T, Paraskevopoulou E, Paraskevopoulou P, Patsilinakos S, Triposkiadis F, Skoularigis J (2017) Red blood cell distribution width as a prognostic marker in patients with heart failure and diabetes mellitus. Cardiovasc Diabetol 16:81. https://doi.org/10.1186/ s12933-017-0563-1

34. Huang S, Zhou Q, Guo N, Zhang Z, Luo L, Luo Y, Qin Z, Ge L (2021) Association between red blood cell distribution width and in-hospital mortality in acute myocardial infarction. Medicine 100:e25404. https://doi.org/10.1097/MD.0000000000025404

35. Hald EM, Lochen ML, Lappegard J, Ellingsen TS, Mathiesen EB, Wilsgaard T, Njolstad I, Braekkan SK, Hansen JB (2020) Red cell distribution width and risk of atrial fibrillation and subsequent thromboembolism: the tromso study. TH Open 4:e280-e287. https://doi.org/10.1055/s-0040-1716417

36. Horne BD (2012) A changing focus on the red cell distribution width: why does it predict mortality and other adverse medical outcomes? Cardiology 122:213-215. https://doi.org/10.1159/ 000341244

37. Yazici P, Demir U, Bozkurt E, Isil GR, Mihmanli M (2017) The role of red cell distribution width in the prognosis of patients with gastric cancer. Cancer Biomark A 18:19-25. https://doi.org/10. 3233/CBM-160668

38. Koma Y, Onishi A, Matsuoka H, Oda N, Yokota N, Matsumoto Y, Koyama M, Okada N, Nakashima N, Masuya D, Yoshimatsu H, Suzuki Y (2013) Increased red blood cell distribution width associates with cancer stage and prognosis in patients with lung cancer. PLoS ONE 8:e80240. https://doi.org/10.1371/journal. pone. 0080240

39. Hu L, Li M, Ding Y, Pu L, Liu J, Xie J, Cabanero M, Li J, Xiang R, Xiong S (2017) Prognostic value of RDW in cancers: a systematic review and meta-analysis. Oncotarget 8:16027-16035. https:// doi.org/10.18632/oncotarget.13784

40. Ge S, Lin S, Zhang L, Zeng M (2020) The association of red blood cell distribution width to platelet count ratio and 28-day mortality of patients with sepsis: a retrospective cohort study. Ther Clin Risk Manag 16:999-1006. https://doi.org/10.2147/TCRM.S2685 23

41. Li M, Xia H, Zheng H, Li Y, Liu J, Hu L, Li J, Ding Y, Pu L, Gui Q, Zheng Y, Zhai Z, Xiong S (2019) Red blood cell distribution width and platelet counts are independent prognostic factors and improve the predictive ability of IPI score in diffuse large B-cell lymphoma patients. BMC Cancer 19:1084. https://doi.org/10. 1186/s12885-019-6281-1

42. Ji Y, Sheng L, Du X, Qiu G, Su D (2015) Elevated platelet count is a strong predictor of poor prognosis in stage I non-small cell lung cancer patients. Platelets 26:138-142. https://doi.org/10.3109/ 09537104.2014.888547

43. Liu S, Fang J, Jiao D, Liu Z (2020) Elevated platelet count predicts poor prognosis in breast cancer patients with supraclavicular lymph node metastasis. Cancer Manage Res 12:6069-6075. https://doi.org/10.2147/CMAR.S257727

44. Lucotti S, Muschel RJ (2020) Platelets and metastasis: new implications of an old interplay. Front Oncol 10:1350. https://doi.org/ 10.3389/fonc. 2020.01350

45. Buergy D, Wenz F, Groden C, Brockmann MA (2012) Tumorplatelet interaction in solid tumors. Int J Cancer 130:2747-2760. https://doi.org/10.1002/ijc. 27441

46. Krol I, Castro-Giner F, Maurer M, Gkountela S, Szczerba BM, Scherrer R, Coleman N, Carreira S, Bachmann F, Anderson S, Engelhardt M, Lane H, Evans TRJ, Plummer R, Kristeleit R, Lopez J, Aceto N (2018) Detection of circulating tumour cell clusters in human glioblastoma. Br J Cancer 119:487-491. https://doi. org/10.1038/s41416-018-0186-7

47. Alix-Panabieres C, Pantel K (2014) Challenges in circulating tumour cell research. Nat Rev Cancer 14:623-631. https://doi. org/10.1038/nrc3820

48. Chen B, Ye B, Zhang J, Ying L, Chen Y (2013) RDW to platelet ratio: a novel noninvasive index for predicting hepatic fibrosis and cirrhosis in chronic hepatitis B. PLoS ONE 8:e68780. https://doi. org/10.1371/journal.pone.0068780

Publisher's Note Springer Nature remains neutral with regard to jurisdictional claims in published maps and institutional affiliations. 